\title{
Sex and Gender
}

Beyond the Binaries

Joy L. Johnson

Robin Repta

Research variables_ “"sex" polarized as "females" and "males," "sexuality" polarized as "homosexuals" and "heterosexuals," and "gender" polarized as "women" and "men"-reflect unnuanced series that conventionalize bodies, sexuality, and social location. Such research designs cannot include the experiences of hermaphrodites, pseudohermaphrodites, transsexuals, transvestites, bisexuals, third genders, and gender rebels as lovers, friends, parents, workers, and sports participants. Even if the research sample is restricted to putative "normals," the use of unexamined categories of sex, sexuality, and gender will miss complex combinations of status and identity, as well as differently gendered sexual continuities and discontinuities. (Lorber, 1996, p. 144)

Eor more than a decade researchers such as Lorber $(1996,2005)$ have challenged us to carefully reconsider the ways that we use the terms gender and sex in research. Despite these challenges, health researchers, on those occasions when they have considered sex and gender in their research, have tended to rely on conceptually stagnant notions of gender and sex that contrast masculine males with feminine females. "Moving beyond the binary" involves two important elements: first, reconsidering how we have conceptualized distinctions between masculine/feminine and male/female, and second, rethinking conceptualizations of gender as strictly social and of sex as strictly biological. A serious problem faced by 
researchers is that our methods have not kept pace with our theoretical work in the area of sex and gender. A research design provides a blueprint for a research project. The way sex and gender are conceptualized has implications for all aspects of the design including the methodological approach, the data collection procedures, and analytic techniques. Incorporating gender and sex into a research design therefore requires consideration of all these elements. For example, while gender is typically theorized as a multidimensional, context-specific factor that changes according to time and place, it is routinely assumed to be a homogeneous category in research, measured by a single check box (Knaak, 2004). Furthermore, even in social science research where theories of gender originated, dangerous and static associations between women and femininity and men and masculinity are often assumed, eroding much of the diversity that exists within and among these categories (Dworkin, 2005). If the science of gender and health research is to advance, we must also consider ways not only to continually refine our base concepts, but also to promote interplay and praxis between theory and method.

With respect to sex, in health research, when it is conceptualized as a binary biological category (male and female), studies are often designed to compare two groups on particular parameters. While this approach is appropriate in some studies, it obfuscates the variation that occurs within and across sex with respect to genetics, anatomy, and physiology and also detracts from the fluid continuum of sex-related characteristics (Johnson, Greaves, \& Repta, 2007). The same holds true for gender: If a study is guided by a conceptualization of gender that focuses on the roles that women and men hold in society, this will have implications for the research design. As Addis and Cohane (2005) attest, "Understanding the social context of masculinity (and gender more broadly) is similar to understanding the social context of race and ethnicity. Approaching important questions from only one perspective of difference is a bit like assuming we can only understand one racial, cultural, or ethnic group by comparing it with another. . . . Gender is about much more than sex differences between men and women on interesting dependent variables" (p. 635). To date, in health research there has been a lack of precision related to conceptual definitions of sex and gender and subsequent design. Researchers have tended to indicate that they are using a gender analysis or focusing on sex differences without appropriately delineating which aspects of gender or sex are of interest. Researchers need to move toward increased conceptual clarity and methodological precision. In this chapter we discuss various ways that sex and gender can be conceptualized and the implications of these conceptualizations for research design.

Before proceeding, it is important to reflect on research as a gendered practice. Science is a social enterprise, not created in a vacuum but influenced by societal opinions and politics. Scholars have investigated the ways that science has changed over the years, drawing attention to women's involvement in the scientific enterprise and detailing how societal shifts in 
gender roles have contributed to different research foci, methods, and epistemologies (Schiebinger, 1999). The fact that these changes have occurred emphasizes the socially constructed nature of research. Research design is similarly gendered as the questions we ask and the methodologies and methods we use are influenced by our gender as researchers and by gendered ideas about "hard" and "soft" research approaches. These types of distinctions underlie power dynamics in science, claims about the legitimacy of various scientific approaches, and distinctions made between biomedical/clinical research and social science research. For example, while clinical trials are now the universally accepted standard for clinical and health policy and practice, this is only one "way" of knowing, which has been shown to serve the financial interests of the physicians and research institutions that conduct this type of research (Mykhalovskiy \& Weir, 2004). In light of the gendered nature of the scientific process, it behooves us to consider not only the ways that conceptualizations of gender influence design but also the ways that our research processes and research institutions are imbued with gender bias.

Sex is a biological construct that encapsulates the anatomical, physiological, genetic, and hormonal variation that exists in species. Our knowledge and understanding of sex has changed as we have come to appreciate the great diversity that exists within populations. For example, previous conceptions of sex assumed chromosomal arrangements XX and XY as the typical makeup for women and men, respectively, while we now understand that chromosomal configurations XXX, XXY, XYY, and XO exist, as well as XX males and XY females (de la Chapelle, 1981; McPhaul, 2002). The existence of these chromosomal arrangements has led to greater understanding of the genetic contributions of $\mathrm{X}$ and $\mathrm{Y}$ chromosomes to human phenotypic development and health (de la Chapelle, 1981) and indicates the need for research to expand narrow conceptualizations of sex to include this type of diversity. Within and across sex categories, variation also exists with respect to metabolic rate, bone size, brain function, stress response, and lung capacity. This variation cannot be captured by simple "male" and "female" designations, which is why it is important to think about sex in more than binary terms.

Conceptualizing sex accurately is important because of the great influence it has on health. There are many sex differences in the development of diseases such as coronary heart disease, Alzheimer's disease, and lung cancer, but the causal mechanisms that account for these differences are not always clear. To begin to identify these mechanisms we must conceptualize sex more precisely. Sex affects health, beginning with the different chromosomal compositions assigned to the sexes, which leads to variation 
in body shape and size, metabolism, hormonal and biochemical profiles, fat and muscle distribution, organ function, and brain structure, among other differences (Clow, Pederson, Haworth-Brockman, \& Bernier, 2009; Johnson et al., 2007). These differences have profound influences on disease etiology, susceptibility, and development. There are numerous examples of this influence. Sex-based differences exist with respect to prescription and illicit drug uptake and response due to differences in metabolism, blood chemistry, and hormonal composition. For similar reasons, the effect of anesthetics varies according to sex. An individual's risk for myocardial infarction is greatly influenced by his or her levels of estrogen, which is a function of sex. In this way, research has confirmed both subtle and vast biological differences between and among the sexes, which has led to the realization that "every cell is sexed" (Institute of Medicine, 2001), affirming the importance of including sex variables in all types of health research.

While we often like to think of sex as biological and gender as social, both concepts are socially constructed and therefore subject to change over time. The ways we parse the categories male, female, intersex, and other are not biologically inherent but relative to place and time. Different cultures conceptualize sex variation in different ways, and our understandings of sex have changed over time (and continue to change) as biological variation is discovered and measurement techniques are refined. For example, procedures for assessing babies' sex at birth have evolved in recent years, particularly in the wake of the intersex movement that actively advocates for those whose reproductive or sexual anatomy is not clearly male or female, and can now include genetic and chromosomal reviews in addition to visual assessment of the genitals (Fausto-Sterling, 2000). Furthermore, in the space of a few decades, the treatment of intersex bodies has changed; assignment surgery at birth (where genitals and secondary sex characteristics are made to look male or female) is no longer widespread due to controversy over the physical, emotional, and sexual harm it can cause (Fausto-Sterling, 2000). Conceptualizing sex as a changing and fluid multidimensional construct ensures that these types of important biological variations are captured in research, ensuring that the needs of all individuals are considered. Comprehensive conceptualizations of sex are also essential for ensuring that more accurate and rigorous science gets carried out in order to identify the causes and importance of sex-related differences across the continuum (Clow et al., 2009).

\section{Gender}

Like sex, gender is a multidimensional construct that refers to the different roles, responsibilities, limitations, and experiences provided to individuals 
based on their presenting sex/gender. Gender builds on biological sex to give meaning to sex differences, categorizing individuals with labels such as woman, man, transsexual, and hijra, ${ }^{1}$ among others. These categories are socially constructed, as humans both create and assign individuals to them. Thus, like sex, ideas about gender are also culturally and temporally specific and subject to change. Gender is often an amorphous concept. When we use the term in everyday conversation, it is not always clear what is being referred to. In what follows we describe approaches to conceptualizing gender: institutionalized gender, gender as constrained choice, gender roles, gender identity (including masculinities and femininities), gender relations, and gender as performance (embodied gender). We also discuss postgenderism as a means of thinking beyond the dyadic gender order. We recognize that there are other conceptualizations but offer these particular angles of vision to illustrate the ways that gender spans the micro to the macro and how conceptualizations vary in specificity and theoretical application.

\section{INSTITUTIONALIZED GENDER}

Gender is both produced and shaped by institutions such as the media, religion, and educational, medical, and other political and social systems, creating a societal gender structure that is deeply entrenched and rarely questioned, but hugely influential. Institutionalized gender refers to the ways that gender is rooted in and expressed through these large social systems, through the different responses, values, expectations, roles, and responsibilities given to individuals and groups according to gender (Johnson et al., 2007). For example, women are often paid less than men for similar work, and workplaces are often gendered, with certain departments and even entire occupations dominated by a particular gender. While gender is context-specific and subject to change, in almost every society in the world, men are more highly regarded than women and given greater power, access, money, opportunities, and presence in public life. The fact that these differences exist on such a large scale points to the embeddedness of institutionalized gender. Institutionalized gender also interacts with systems related to race, class, sexual identity, and other social constructs to further organize individuals and groups into hierarchies of privilege. Institutionalized gender is an important concept to consider in health research as it structures people's lives in ways that both permit and limit health by influencing, for example, experiences within and access to health care systems, resulting in different exposure risks and care received. Furthermore, vast differences

\footnotetext{
${ }^{1}$ Hijra is a South Asian term that refers to a third gender that is considered neither male nor female, although hijra are typically phenotypic men who wear female clothing (Reddy, 2005).
} 
exist among the genders with respect to power and privilege within society, which affects health on a number of levels (e.g., financial stability is related to food security, safe neighborhoods, and good health care). For example, a Canadian study by Borkhoff et al. (2008) found that two times more men than women received total knee arthroplasty (TKA) despite similar levels of disability and symptoms. The authors' assertion that physicians consciously or unconsciously judge who is more likely to need and benefit from TKA based on presenting gender can be seen as an example of institutionalized gender as the findings indicate a systemic advantage associated with male gender (Borkhoff et al., 2008). Furthermore, Borkhoff et al. hypothesize that gender roles influence physician-patient interactions and that women's narrative speaking style is not as effective as men's factual and direct style when seeking help for injured knees. In both cases, gender biases affect health at the institutional level.

\section{GENDER AS CONSTRAINED CHOICE}

Bird and Rieker (2008) conceptualize gender as a series of constrained choices that impact health in complex ways. They contend that individuals make decisions about health within broader contexts of power and privilege where gender, in addition to other social determinants, affords varying levels of influence, control, access, and opportunity. So while individuals are likely aware of how to improve their health, structural factors such as time, money, and power can encourage or discourage healthy behavior (Bird \& Rieker, 2008). Bird and Rieker's model of gender and health is unique in that it acknowledges the impact of both biological and social health influences and addresses how both intersect to produce health. Bird and Rieker argue that research on gender differences in health that focuses on biological processes needs to account for sociostructural constraints, while social research needs to acknowledge the ways that people's "choices" are mediated by biology. For example, women's role as caregiver can influence the amount of time they have to spend on health-promoting behaviors and activities (Bird \& Rieker, 2008). Stress resulting from time constraints can affect and are affected by present cardiovascular and immune health, illustrating some of the interplay between sex and gender (Bird \& Rieker, 2008). When investigating the impact of gender as a constrained choice, Bird and Rieker encourage asking the following questions: "Whose responsibility is health? Are protective measures, preventative behaviours, and the costs and consequences of poor health practices the province of individuals, families, the workplace, communities, states or some combination of these?" (p. 214). Viewing gender as a constrained choice therefore involves addressing the health restrictions that occur at many levels (individual, family, community, society) and acknowledging that healthy "choices" are limited by these overarching and intersecting constraints. 
Andersson (2006; Andersson, Cockcroft, \& Shea, 2008) uses a similar concept to constrained choice in his work on HIV/AIDS prevention in southern African countries, arguing that current prevention initiatives incorrectly assume that individuals are free to make "healthy choices." Andersson (2006) argues that promoting abstinence, condom use, microbicides, male circumcision, and the reduction of concurrent partnerships (all of which have been recommended in the literature) does not address the needs of individuals who are "choice disabled," or unable to use prevention tools as a result of power inequities. For example, individuals who are victims of sexual violence are unable to remain abstinent or insist on condom use, and health messages about limiting the number of sexual partners are rendered useless in the face of violence (Andersson, 2006). The notion of "choice disability" (Andersson, 2006) has applicability beyond the HIV/AIDS realm as many health behaviors and perceived health "choices" are in fact structured by contextual dynamics such as power, gender, socioeconomics, and so forth.

\section{GENDER ROLES}

Gender roles can be described as social norms, or rules and standards that dictate different interests, responsibilities, opportunities, limitations, and behaviors for men and women (Johnson et al., 2007; Mahalik et al., 2003). Gender roles structure the various "parts" that individuals play throughout their lives, impacting aspects of daily life from choice of clothing to occupation. Informally, by virtue of living in a social world, individuals learn the appropriate or expected behavior for their gender. While individuals can accept or resist traditional gender roles in their own presentation of self, gender roles are a powerful means of social organization that impact many aspects of society. For this reason, individuals inevitably internalize conventional and stereotypic gender roles, irrespective of their particular chosen gender, and develop their sense of gender in the face of strong messaging about the correct gender role for their perceived body. Gender roles shape and constrain individuals' experiences; men, women, and other genders are treated differently and have diverse life trajectories as a result of their ascribed role and the degree to which they conform.

Conventional, dualistic understandings of gender roles are problematic, inasmuch as they are not representative of the diversity that exists within and across populations. The embeddedness of dyadic gender roles in society also contributes to the discrimination of individuals who do not conform to these prescribed roles. Furthermore, the notion of gender as a role obfuscates the performative and distinctive nature of gender, instead suggesting a situated and static function (West \& Zimmerman, 1987). Despite these issues, many scales have been developed to measure aspects of gender roles, the degree to which individuals take up these roles, and the 
effects of these roles on human health, well-being, and relationships (Bem, 1981; Eisler, Skidmore, \& Ward, 1988; Mahalik et al., 2003; O’Neil, Helms, Gable, David, \& Wrightsman, 1986). For example, Leech (2010) used data from the National Longitudinal Survey of Youth in the United States, which included a scale of attitudes toward traditional gender roles, and found that moderate gender role attitudes were associated with safer sex practices among sexually active young women. Leech theorizes that by having more fluid and egalitarian gender roles, young women challenge traditional conceptions of femininity, which promote subservience in sexual relationships, and instead bring greater awareness to their negotiations about safer sex. It is important to note that the more nuanced measure of gender used in this study enabled Leech to identify moderate gender role attitudes as a protective factor; Leech emphasizes that "scholars who remain interested in gender role orientations as an explanation for various social differences ... should take particular care to measure the concept of gender role attitudes on a spectrum" (p. 442).

When considering the measurement of gender roles, it is also important to recognize that many measures are criticized for being "crude" or imprecise (Choi \& Fuqua, 2003), and for a lack of reliability and validity (yielding inconsistent results across scales that purport to measure similar constructs) (Beere, 1990). Many scales also confuse the terms sex and gender, using them synonymously and thus incorrectly (e.g., the Bem Sex Role Inventory actually measures gender). Finally, recent research suggests that societal perceptions of appropriate feminine and masculine traits have changed in North America somewhat (Seem \& Clark, 2006), which calls the accuracy of decades-old scales into question and highlights the temporal nature of socially constructed categories. Despite these issues, the prevalence of psychological research using gender role scales makes this aspect of gender one of the most frequently cited within the literature, although again, due to insufficient conceptualizations, the scales may actually measure phenomena other than gender roles.

\section{GENDER IDENTITY}

A great deal of feminist theorizing on gender identity is based on philosophical understandings of identity as reflexive self-relation (Butler, 2004; de Beauvoir, 1953/1974). Gender identity is similar to other social identities in that it relates to physical embodiment, and is mediated by people's relative location within their social environment and how they are judged by others, but ultimately is concerned with how people view themselves with respect to gender. Individuals' inner feelings impact how they present themselves as a man, a woman, or another gender. Gender identities develop within gendered societies, where the pressure to adopt the "correct" and "corresponding" gender according to presenting sex is strong. 
Consequences exist for individuals who defy the gender order: In many parts of the world having an unclear gender presentation can result in discrimination, violence, and even death (Whittle, 2006).

Furthermore, even within societies where different and fluid gender presentations are more accepted, authors have discussed the uncomfortable evaluation that occurs when a person's gender is unclear and the seemingly human need to "sort" individuals according to the two-gender system (Namaste, 2009). Individuals thus internalize aspects of institutionalized gender and gender roles and negotiate their own gender identity in relation to the dyadic gender model. In this way, the conventional gender order is reinforced. The combined influence of internal feelings and social pressures guides gender identity development, impacting how individuals feel as gendered persons and constraining their behavior based on what they think and experience as acceptable for their given gender.

For example, Oliffe (2006), in his study of older men's experiences of androgen deprivation therapy (ADT) for advanced prostate cancer, found that the men's experiences of illness impacted the way they felt about themselves and their feelings of masculinity. After receiving ADT and experiencing subsequent body and mind changes, the men renegotiated their gender identities. While still constructed against hegemonic ideals of masculinity, the men's masculine selves were altered by physical, social, and sexual changes, which prevented them from "doing" their masculinity in conventional ways (Oliffe, 2006). Oliffe's study examines the socially constructed interpretation of men's physical changes as a result of ADT and therefore offers a unique means of approaching health issues where both sex and gender are at play. This example also demonstrates the interaction between sex and gender. Physiological sex affects social gender and vice versa, blurring the distinct categories that feminists fought so hard to separate and distinguish. While we discuss this in more depth later in the chapter, it is important to recognize here that sex and gender are dependent on each other for both meaning and the production of health. Because sex and gender interact to affect health status and generate health outcomes, research designs that are able to capture physiological and social measures are very useful. Furthermore, research that is able to theorize about the mechanisms behind sex and gender health interactions is particularly relevant.

\section{MASCULINITY}

Masculinity is a socially constructed component of gender that is typically associated with men and male characteristics, though this strict association has been problematized. Instead of associating masculinity with particular bodies, it is instead popularly theorized to be a range of behaviors, practices, and characteristics that can be taken up by anyone. 
For example, Halberstam (1998) has made the case for female masculinity. Masculinity is therefore not a singular concept; multiple and conflicting masculinities have been identified that have varying degrees of power and that are born from different social contexts (Connell, 2005). For example, Connell (2005) has described the subordination of gay men by heterosexual men as a function of differing levels of power among the masculinities, with subordinate masculinities often conflated with femininity. Hegemonic masculinity is a particularly dominant form of masculinity, and while not static in any way, in most cultures it emphasizes strength, aggression, courage, independence, and virility (Connell \& Messerschmidt, 2005). Hegemonic masculinity is also associated with heterosexual, White, middle-class status in Western cultures (Noble, 2004; Schippers, 2007). Masculinity is not stagnant and must be constantly maintained and reproduced through various gendered practices and behaviors. In this way, masculinity is best understood as a "floating signifier," given meaning by human-constructed language and the bodies that reproduce it (Schippers, 2007).

Masculinity can affect health. "Risky" health behaviors have been linked to hegemonic masculinity, as masculine individuals are encouraged to be strong in the face of illness, deny ill health or "weakness," and decline health services or interventions as a means of "being tough" (Connell \& Messerschmidt, 2005; Lyons, 2009; Moynihan, 1998). As previously discussed, understandings and experiences of masculinity vary according to other social locations. In this way, Mullen, Watson, Swift, and Black (2007) note the emergence of multiple masculinities in their study of young men, masculinities, and alcohol consumption in Glasgow, Scotland. The authors discuss the ways in which different drinking cultures (e.g., mixed-sex clubs as opposed to traditional male-dominated pubs) and varying socioeconomic and educational backgrounds result in more flexible masculine roles and drinking behaviors for young men today, particularly when compared with the experiences of previous generations. For example, the young men's attitudes toward drinking tended to change with age, as their definitions of an enjoyable evening became affected by work responsibilities, finances, family obligations, and sports (Mullen et al., 2007). The authors contend that "we are witnessing a move away from the conventional hegemonic masculine role to a more pluralistic interpretation" (Mullen et al., 2007, p. 162). Health behaviors can thus be implicated in the construction and maintenance of the gender order.

\section{FEMININITY}

Like the connections often made between masculinity and maleness, femininity is often associated with femaleness, when it in fact is not inherently attached to any particular bodies and instead is constructed and 
reproduced through individuals' practices and behaviors in their everyday lives. While "emphasized femininity," along with multiple other overlapping femininities, has been described, these concepts are less developed than masculinities and require additional theoretical and empirical work (Connell \& Messerschmidt, 2005; Schippers, 2007). While it has been suggested that no femininity is hegemonic, Connell (1987) offers the concept of "emphasized femininity" as a prioritized form of femininity, characterized by its domination by masculinity, which is a crucial component in men's supremacy over women in the gender order. In this way, all femininities are constructed as subordinate to masculinities (in particular hegemonic masculinity), and it is through this subordination that gender hegemony is created and maintained (Connell, 1987). It is important to note that while masculinity is prioritized as the "gold standard," both masculinity and femininity are constructed through their differences to each other. This is an important aspect of gender hegemony.

While femininity can affect health by encouraging individuals to take an interest in their health, it can also encourage feminine individuals to prioritize the health of children or other family members above their own, as part of a nurturing and caring ideal. Research has also demonstrated that high levels of masculinity but not femininity are associated with good mental health among adolescents, which is posited to be the result of many accumulated privileges associated with masculinity throughout the teenage years (Barrett \& White, 2002). In finding that characteristics typically associated with boys and men improve the mental health of both sexes, interesting questions are raised about the way we value femininity in our society. In this way, scholars have problematized the positioning of femininity as "other," distinctly different from masculinity as opposed to a function of the gender system in its own right, both within society and reproduced in gender theorizing and research (Schippers, 2007). Research on femininities needs to interrogate the way in which femininities are oppressed and subjugated by masculinity.

\section{GENDER RELATIONS}

Gender operates relationally by influencing our expectations and understandings of others, and the ways in which we relate to and interact with them (Johnson et al., 2007). For example, within romantic relationships, ideas about who should initiate contact, pay for dinner, and drive on dates are all gendered. Gender relations describe the ways that relationships are guided by gendered expectations and understandings that can limit or expand our opportunities in various situations. In research, acknowledging the relational impact of gender is important in order to assess how health behaviors and relationships change in the presence of shifting gender dynamics. As Clow et al. (2009) contend, "Because gender is relational, 
we need to consider both the variety and hierarchy of gender roles and identities when we explore the links between gender and health" (p. 13).

In their study of couple interactions on women's tobacco reduction postpartum, Bottorff, Kalaw, et al. (2006) found that the gendered relationships between men and women affect women's rates of quit relapse. For example, when both partners smoke, women's tobacco reduction or cessation is often mediated by their partner's support or hindrance and strongly influenced by the social shame associated with women's smoking during pregnancy (Bottorff, Kalaw, et al., 2006). Furthermore, women's tobacco reduction during pregnancy and postpartum often offers their male partners an opportunity to reduce or quit smoking, which positions expectant and new fathers as uniquely primed to receive tobacco reduction or cessation messages (Bottorff, Oliffe, Kalaw, Carey, \& Mróz, 2006). In light of these gendered findings, intervention efforts can consider the gendered roles of new parents when designing tobacco reduction or cessation programs, while also focusing on the health of the expectant and new mothers and fathers and not just the well-being of the fetus or infant (Bottorff, Kalaw, et al., 2006; Bottoff, Oliffe, et al., 2006).

\section{GENDER AS PERFORMANCE (EMBODIED GENDER)}

Gender has been theorized as a performance, constructed through the everyday practices of individuals (Butler, 1988; Lyons, 2009). Gender is manifested in the ways that individuals style their bodies and carry themselves, and also in how they speak and move (Butler, 1988, 2004). In this way, gender is not only produced by and on particular bodies but is also located within particular activities, behaviors, and practices. It is through the "stylized repetition" of these gendered practices (e.g., body gestures, mannerisms) that gender is performed (Butler, 1988, 2004). Furthermore, as Lyons (2009) explains, "Through engagement in these behaviours or practices, gender becomes accountable and assessed by others, and aspects of gendered identity become legitimated" (p. 395). Therefore, gender becomes embodied.

West and Zimmerman $(1987,2009)$ use the idea of gender performance in their highly regarded paper, "Doing Gender." West and Zimmerman's linguistic emphasis on the way gender is "done" underscores the conscious and unconscious production of gender in all social interactions and relationships. They also emphasize the accountability of gender within the dichotomous sex/gender system where individuals must perform gender if they wish to make themselves, and their actions, accountable. West and Zimmerman (1987) articulate that "actions are often designed with an eye to their accountability, that is, how they might look and how they might be characterized. The notion of accountability also encompasses those actions undertaken so that they are specifically unremarkable and thus not 
worthy of more than a passing remark, because they are seen to be in accord with culturally approved standards" (p. 136). While this may appear to make gender a solely personal and conscious endeavor, West and Zimmerman point out that gender is also implicated in all social relationships and at the institutional level, which enforces the production of gender. Everyone is therefore complicit in the maintenance of the gender order. Finally, "doing gender" reinforces essentialist arguments about differences between men and women, concealing the socially constructed nature of such differences and perpetuating the status quo subordination of women and femininities (West \& Zimmerman, 1987, 2009). Using the concept of "doing gender" in research can direct attention to the ways in which health practices can be seen as forms of gender performance and the visceral enactment of gender hierarchies.

\section{POSTCENDERISM}

Postgenderism confronts the limits of a social constructionist account of gender and sexuality, and proposes that the transcending of gender by social and political means is now being complemented and completed by technological means. (Hughes \& Dvorsky, 2008, p. 2)

Some theorists argue that to address concerns with the conventional dyadic gender system, we need to move beyond it. The concept of postgenderism arose within feminist discussions of gender. Postgender perspectives typically advocate the dissolution of narrow and restricting gender roles as a means of emancipating women from patriarchy (Haraway, 1991). Postgenderism also posits that technologies, especially bio- and reproductive technologies, can erode strict binary gender roles to help create a postgender society (Haraway, 1991; Hughes \& Dvorsky, 2008). The idea that technology has the potential to alter social norms and relationships is not new. For example, it is well established that the birth control pill contributed, in part, to White, middle-class North American women's liberation from the home and their increased participation in the workforce in the 1960s. Hughes and Dvorsky (2008) argue that "our contemporary efforts at creating gender-neutral societies have reached the limits of biological gender" (p. 13), and thus they discuss a range of technologies and medical advancements that have the potential to radically blur the distinctions between categories of gender, sex, and sexuality. The possibility of artificial wombs, parthenogenesis (a type of asexual reproduction that occurs in female animal and plant species where fertilization occurs without males), cloning, and same-sex reproduction are offered as examples of technologies that can change the way we reproduce and therefore classify human beings (Hughes \& Dvorsky, 2008). Furthermore, surgeries that can create and modify genitals, electronic sex toys that connect participants via 
computer (teledildonics), and the psychopharmacological possibility of "de-gendering" the human brain using hormones all provide ways of thinking about a postgender world and highlight the breadth and variety of human gender, sex, and sexuality (Hughes \& Dvorsky, 2008).

Postgenderism is often believed to offer a more egalitarian and just system, where individuals are not sexed at birth and instead are classified according to other means, for example, age, talents, and interests (Lorber, 2005). Postgender theories raise provocative questions about the role of gender and ethical concerns about the impact of technologies. If we are indeed able to (even in part) dismantle or move beyond the conventional gender order, does this mean gender will no longer impact human health? In research terms this question can also be raised with respect to measurement: Is it possible to independently measure all the aspects that contribute to gender differences in health (e.g., power, income, household responsibilities)? If so, can this fully account for the effects of gender? Or is there something about gender and gendered bodies, in whatever form they exist, that influences health?

\section{Sexual Identity}

Gender and sexual identity are often confounded within the literature, and for good reason. Matters of gender identity and sexual identity are closely linked. However, it is problematic to use these terms synonymously as there are important conceptual differences. Gender and sexual identity are different because people who hold a particular sexual identity (e.g., lesbian) can take on a range of gender identities.

The effects of sexual identity are all too commonly ignored or narrowly constructed in health research. Categorical limitations that are in part created by limited language and exacerbated by negative societal stereotypes diminish the sexual variation that exists within populations, which is reproduced within research. Compulsive heterosexuality (Rich, 1994) is a term that refers to heterosexuality as the default sexual orientation and as an organizing principle within societies that privileges and normalizes heterosexual relationships while discriminating against and discouraging all other sexual orientations and relationships. In health research, heterosexuality is usually the assumed default, which ignores the influence of sexual identity and the ways that sexual identity interacts with gender to produce unique health outcomes. Furthermore, Butler (1999) contends that heterosexual desire plays an important role in constructing masculinity and femininity as opposing genders. She argues that within dominant heterosexuality, the object of masculine desire is inherently feminine, while the object of feminine desire is inherently masculine (Butler, 1999). Hence, sexuality is linked to the construction of gender identity. 
Matters of sexual identity force us to think about gender in new ways and have pushed the frontiers of queer/gender theory.

\section{Implications for Research Design}

The feminist sex/gender distinction has had unintended consequences. Underlying this conceptual dichotomy is the idea that sex is a fixed natural binary; sex is not seen as a process but as a self-evident fact. ... [U]ntil gender scholars theorize sex as a social construction, notions of naturally binary sex will continue to act as a lodestone in our thinking and essentialist arguments will retain persuasive power. (Friedman, 2006, p. 1)

As the above quote describes, feminist theorizing about sex and gender has resulted in conceptualizations of singular "natural" binary categories. Unfortunately, the complexity of sex and gender is rarely captured in health research, where sex is typically measured using two categorical options and gender is neglected, limiting the scope and relevance of research results (Bird \& Rieker, 2008; Hughes \& Dvorsky, 2008). Recognizing that sex and gender are complex concepts, many elements of which exist on continua, influences the ways in which research is framed and organized. Relying on the male-female/masculine-feminine binary invariably homogenizes research participants and results, masking the variation that is inherent in populations. With growing calls for inclusivity and rigor in research, it is important to capture the variation within and across groups in order to study and account for these differences.

It is also important to acknowledge the ways that sex and gender, while distinct concepts, are inextricably linked and related. The social aspects of gender can map onto biology to create, maintain, or exacerbate physiological differences that are already established (Bird \& Rieker, 2008). Sex and gender also mutually influence each other as feedback loops. For example, the incidence of melanoma is influenced by gendered bathing suit styles that expose different areas of the body, leading men to develop more trunk and midback lesions than women (Bulliard, Cox, \& Semenciw, 1999; Pérez-Gómez et al., 2008). Sun exposure is further gendered by the different occupations and outdoor activities taken up by individuals, as well as by different clothing styles, gendered ideas about sunscreen use, and socioeconomic status that enables travel to sunny locations (Bulliard et al., 1999; Pérez-Gómez et al., 2008). This shapes who develops melanoma and where. These gender-specific factors are further compounded by both biological and gendered factors, as once melanoma has developed, the presence of estrogen is believed to affect the progression of the disease, while gendered dynamics related to body awareness, surveillance, 
and prioritizing health prompt individuals to seek medical attention differentially, which affects prognosis (Brady et al., 2000; Institute of Medicine, 2001; Pérez-Gómez et al., 2008). In this way, most health-related differences between men and women have both social and biological antecedents, confounding the distinction between sex and gender. This makes it challenging to distinguish whether sex or gender is at play and also complicates the search for the mechanisms that cause health differences. In research, it is important to acknowledge the conceptual differences between sex and gender, but also to recognize the ways that these concepts work in tandem to produce health.

When incorporating sex or gender into a research study, it is important to identify which specific aspects of these concepts are of interest. What is it about sex that is relevant to your particular topic? What relationship or aspects of gender are you interested in studying? Identifying the relevant aspects of sex and gender for a study is important as this will shape the measures and means of data collection as well as the types of analytic approaches used. In getting started, one might begin by considering the question: What sex- or gender-based mechanism influences the outcome of interest? Considering this question helps us to theorize about the relevant aspects of sex and gender that may be at play. These theoretical tenets or hypotheses lay the conceptual foundation for a study focused on sex and/or gender and health. For example, in considering sex and gender and health outcomes related to depression, one might ask if the different symptoms reported by men and women are related to biological factors (e.g., hormones) or social factors (e.g., hegemonic masculinities that influence the reporting of symptoms) or biases inherent in our measures of depression (e.g., a form of institutionalized gender). These are but three of many possible mechanisms that might account for observed difference. Again, the more precise we can be about the mechanisms, the better we will be able to capture these elements in our research design.

\section{Bridging the Solitudes of Theory and Design}

As has been emphasized in this chapter, the way we conceptualize sex and gender has implications for all elements of design including measurement. While this is addressed in Chapters 4 and 5, suffice it to say that underlying every measure of gender, and there are many measures, are particular conceptualizations. For example, the Bem Sex Role Inventory, a commonly used crude measure of gender, measures gender role perception and cannot ascertain elements of institutionalized gender or gender relations (Bem, 1981). Where researchers often fail in developing coherent research designs is in ensuring that the measures specified are in line with the broader conceptualization of gender being used in a study. Thus, theory and design 
often exist as two solitudes in research that are not adequately integrated or resolved. Incorrect or incomplete conceptualizations of sex and gender lead to insensitive and inaccurate analysis. A lack of sophisticated and precise methods and measures also contributes to poor research designs.

\section{Bringing Sex, Gender, and Sexuality Together: The Body as a Contested Frontier}

The human body is an important site of academic theorizing and scholarship. Many theorists have argued that the body serves as a metaphor for culture and society and, as such, that the body can and should be read as a text onto which societal norms and systems such as gender are inscribed (Howson, 2004; Hargreaves \& Vertinsky, 2006; Shilling, 2005). Scholarship on the body raises provocative questions about the intersections and conceptualizations of gender, sex, and sexuality and interrogates assumptions about the connectedness of these categories. Trans- and intersex bodies in particular have disrupted strict and static categories of gender and sex, as these "uncategorizable" bodies highlight the limitations of current conceptualizations (Fausto-Sterling, 2000). For example, both the interpretation of sex differences with respect to endocrine function and the conception process in mammals are gendered narratives that reflect and reinforce different gender roles according to phenotypic sex (Martin, 1991). Because ideas of sex, sexuality, and gender can collide when it comes to the body, research that attempts to bridge the solitudes of theory and design is challenging. Theories of gender, sex, and sexuality constantly shift, making it difficult to implement theories in concrete ways. In this way, the body serves as a final frontier in sex and gender scholarship as it pushes us to think about sexed and gendered bodies and their distinctions and relationships differently.

It is important to note that while transgendered bodies can call our categories of sex and gender into question, they can also confirm and reinforce the conventional gender system in the way that transgendered bodies are judged and evaluated for sex reassignment surgery. Often transgendered individuals desiring surgery conform to strict heteronormative roles in order to legitimize their transition (Hughes \& Dvorsky, 2008). In this way, the medical system restricts individuals' ability to make gender transitions that do not produce normative sexed and gendered bodies (Spade, 2006). For this reason, while most theorists appreciate that the medical system's recognition of gender variance has its benefits (e.g., access to safe treatments and surgeries, insurance coverage), they also acknowledge the ways in which this system reifies a dyadic and rigid view of gender and denigrates bodies that cannot be neatly organized into one of the two conventional gender categories: masculine male and feminine female 
(Fausto-Sterling, 2000; Spade, 2006). Restricting the creation of "postgender" bodies therefore reinforces the conventional gender order.

\section{Conclusion}

Sex and gender are both important and mutually reinforcing concepts. The importance of these two concepts to issues of health cannot be overstated, which is why both need to be considered in health research. Improved theories about the relationships between gender, sex, and health are required in order to develop better methodologies. At the same time, methodologies and methods must keep up with theoretical progress; new and updated and improved methods for gender and health research are required.

\section{References}

Addis, M. E., \& Cohane, G. H. (2005). Social scientific paradigms of masculinity and their implications for research and practice in men's mental health. Journal of Clinical Psychology, 61(6), 633-647.

Andersson, N. (2006). Prevention for those who have freedom of choice-or among the choice-disabled: Confronting equity in the AIDS epidemic. AIDS Research and Therapy, 3(1), 23.

Andersson, N., Cockcroft, A., \& Shea, B. (2008). Gender-based violence and HIV: Relevance for HIV prevention in hyperendemic countries of southern Africa. AIDS, 4, S73-S86.

Barrett, A. E., \& White, H. R. (2002). Trajectories of gender role orientations in adolescence and early adulthood: A prospective study of the mental health effects of masculinity and femininity. Journal of Health and Social Behaviour, 43(4), 451-468.

Beere, C. A. (1990). Sex and gender issues: A handbook of tests and measures. New York: Greenwood Press.

Bem, S. L. (1981). Bem sex role inventory: Professional manual. Palo Alto, CA: Consulting Psychologists Press.

Bird, C. E., \& Rieker, P. P. (2008). Gender and health: The effects of constrained choices and social policies. Cambridge, UK: Cambridge University Press.

Borkhoff, C. M., Hawker, G. A., Kreder, H. J., Glazier, R. H., Mahomed, N. N., \& Wright, J. G. (2008). The effect of patients' sex on physicians' recommendations for total knee arthroplasty. Canadian Medical Association Journal, 178(6), 681-687.

Bottorff, J. L., Kalaw, C., Johnson, J. L., Stewart, M., Greaves, L., \& Carey, J. (2006). Couple dynamics during women's tobacco reduction in pregnancy and postpartum. Nicotine \& Tobacco Research, 8(4), 499-509. 
Bottorff, J. L., Oliffe, J., Kalaw, C., Carey, J., \& Mróz, L. (2006). Men’s constructions of smoking in the context of women's tobacco reduction during pregnancy and postpartum. Social Science \& Medicine, 62(12), 3096-3108.

Brady, M. S., Oliveria, S. A., Christos, P. J., Berwick, M., Coit, D. G., Katz, J., et al. (2000). Patterns of detection in patients with cutaneous melanoma. Cancer, $89(2), 342-347$.

Bulliard, J., Cox, B., \& Semenciw, R. (1999). Trends by anatomic site in the incidence of cutaneous malignant melanoma in Canada, 1969-93. Cancer Causes and Control, 10(5), 407-416.

Butler, J. (1988). Performative acts and gender constitution: An essay in phenomenology and feminist theory. Theatre Journal, 40(4), 519-531.

Butler, J. (1999). Gender trouble: Feminism and the subversion of identity. London: Routledge.

Butler, J. (2004). Undoing gender. New York: Routledge.

Choi, N., \& Fuqua, D. R. (2003). The structure of the Bem sex role inventory: A summary report of 23 validation studies. Educational and Psychological Measurement, 63(5), 872-887.

Clow, B., Pederson, A., Haworth-Brockman, M., \& Bernier, J. (2009). Rising to the challenge: Sex-and gender-based analysis for health planning, policy and research in Canada. Halifax, NS, Canada: Atlantic Centre of Excellence for Women's Health.

Connell, R. (1987). Gender and power. Cambridge, UK: Polity Press.

Connell, R. (2005). Masculinities (2nd ed.). Berkeley: University of California Press.

Connell, R. W., \& Messerschmidt, J. W. (2005). Hegemonic masculinity: Rethinking the concept. Gender \& Society, 19(6), 829-859.

de Beauvoir, S. (1974). The second sex [Deuxième sexe]. New York: Vintage Books. (Original work published in 1953)

de la Chapelle, A. (1981). The etiology of maleness in XX men. Human Genetics, 58(1), 105-116.

Dworkin, S. L. (2005). Who is epidemiologically fathomable in the HIV/AIDS epidemic? Gender, sexuality, and intersectionality in public health. Culture, Health \& Sexuality, 7(6), 615-623.

Eisler, R. M., Skidmore, J. R., \& Ward, C. H. (1988). Masculine gender-role stress: Predictor of anger, anxiety, and health-risk behaviours. Journal of Personality Assessment, 52(1), 133-141.

Fausto-Sterling, A. (2000). The five sexes, revisited. Sciences, 40(4), 18.

Friedman, A. (2006). Unintended consequences of the feminist sex/gender distinction. Genders Online Journal, 43. Retrieved December 11, 2010, from http://www.genders.org/g43/g43_friedman.html

Halberstam, J. (1998). Female masculinity. Durham, NC: Duke University Press.

Haraway, D. J. (1991). Simians, cyborgs, and women: The reinvention of nature. New York: Routledge.

Hargreaves, J., \& Vertinsky, P. A. (2006). Physical culture, power, and the body. Abingdon, Oxon, UK: Routledge.

Howson, A. (2004). The body in society: An introduction. Cambridge, UK: Polity.

Hughes, J., \& Dvorsky, G. (2008). Postgenderism: Beyond the gender binary. IEET White Paper 3. Hartford, CT: Institute for Ethics and Emerging 
Technologies. Retrieved December 11, 2010, from http://ieet.org/archive/ IEET-03-PostGender.pdf

Institute of Medicine. (2001). Committee on understanding the biology of sex and gender differences. In T. M. Wizemann \& M. Pardue (Eds.), Exploring the biological contributions to human health: Does sex matter? Washington, DC: National Academy Press.

Johnson, J. L., Greaves, L., \& Repta, R. (2007). Better science with sex and gender: A primer for health research. Vancouver, BC, Canada: Women's Health Research Network.

Knaak, K. (2004). On the reconceptualizing of gender: Implications for research design. Sociological Inquiry, 74(3), 302-317.

Leech, T. G. J. (2010). Everything's better in moderation: Young women's gender role attitudes and risky sexual behaviour. The Journal of Adolescent Health, 46(5), 437-443.

Lorber, J. (1996). Beyond the binaries: Depolarizing the categories of sex, sexuality, and gender. Sociological Inquiry, 66(2), 143-160.

Lorber, J. (2005). Breaking the bowls: Degendering and feminist change. New York: Norton.

Lyons, A. C. (2009). Masculinities, femininities, behaviour and health. Social and Personality Psychology Compass, 3(4), 394-412.

Mahalik, J. R., Locke, B. D., Ludlow, L. H., Diemer, M. A., Scott, R. P. J., Gottfried, M., et al. (2003). Development of the conformity to masculine norms inventory. Psychology of Men \& Masculinity, 4(1), 3-25.

Martin, E. (1991). The egg and the sperm: How science has constructed a romance based on stereotypical male-female. Signs: Journal of Women in Culture \& Society, 16(3), 485.

McPhaul, M. J. (2002). Androgen receptor mutations and androgen insensitivity. Molecular and Cellular Endocrinology, 198(1-2), 61-67.

Moynihan, C. (1998). Theories in health care and research: Theories of masculinity. British Medical Journal, 317(7165), 1072-1075.

Mullen, K., Watson, J., Swift, J., \& Black, D. (2007). Young men, masculinity and alcohol. Drugs: Education, Prevention and Policy, 14(2), 151-165.

Mykhalovskiy, E., \& Weir, L. (2004). The problem of evidence-based medicine: Directions for social science. Social Science \& Medicine, 59(5), 1059-1069.

Namaste, V. (2009). Undoing theory: The "transgender question" and the epistemic violence of Anglo-American feminist theory. Hypatia, 24(3), 11-32.

Noble,J.B.(2004).Masculinitieswithoutmen? Femalemasculinity in twentieth-century fictions. Vancouver, BC, Canada: UBC Press.

Oliffe, J. (2006). Embodied masculinity and androgen deprivation therapy. Sociology of Health \& Illness, 28(4), 410-432.

O’Neil, J., Helms, B., Gable, R., David, L., \& Wrightsman, L. (1986). Gender-role conflict scale: College men's fear of femininity. Sex Roles, 14(5), 335-350.

Pérez-Gómez, B., Aragonés, N., Gustavsson, P., Lope, V., López-Abente, G., \& Pollán, M. (2008). Do sex and site matter? Different age distribution in melanoma of the trunk among Swedish men and women. British Journal of Dermatology, 158(4), 766-772.

Reddy, G. (2005). With respect to sex: Negotiating hijra identity in South India. Chicago: University of Chicago Press. 
Rich, A. C. (1994). Blood, bread, and poetry: Selected prose, 1979-1985. New York: Norton.

Schiebinger, L. L. (1999). Has feminism changed science? Cambridge, MA: Harvard University Press.

Schippers, M. (2007). Recovering the feminine other: Masculinity, femininity, and gender hegemony. Theory and Society, 36(1), 85-102.

Seem, S. R., \& Clark, M. D. (2006). Healthy women, healthy men, and healthy adults: An evaluation of gender role stereotypes in the twenty-first century. Sex Roles, 55(3), 247-258.

Shilling, C. (2005). The Body in Culture, Technology \& Society. London: SAGE Publications, Ltd.

Spade, D. (2006). Mutilating gender. In S. Stryker \& S. Whittle (Eds.), The transgender studies reader (pp. 315-318). New York: Routledge.

West, C., \& Zimmerman, D. H. (1987). Doing gender. Gender \& Society, 1(2), $125-151$.

West, C., \& Zimmerman, D. H. (2009). Accounting for doing gender. Gender \& Society, 23(1), 112-122.

Whittle, S. (2006). Foreword. In S. Stryker \& S. Whittle (Eds.), The transgender studies reader (pp. xi-xvi). New York: Routledge. 
